\title{
Reported mediation as a function of degree of learning
}

\author{
SANFORD J. DEAN, SYRACUSE UNIVERSITY \\ RANDALL B. MARTIN, NORTHERN ILLINOIS UNIVERSITY
}

The effects of 10 practice trials beyond a criterion of two perfect trials on reported mediation was investigated in an $\mathrm{AB}, \mathrm{BC}, \mathrm{AC}$ paired-associate learning task. Significantly more "direct" responses were reported after the 10 additional trials than after the two perfect trials. Significantly more explicit mediation was reported for facilitation pairs and there was no evidence for "unconscious mediation."

It is a common observation that during early stages of learning responding is accompanied by a great deal of mediational activity and that this activity tends to decrease with practice (O'Brien, 1921; Solomons, 1899). In paired associate learning, for example, mnemonic devices may initially mediate responses but eventually drop out with the responses becoming automatic (Barnes \& Underwood, 1959; Reed, 1918). This relationship was also described by James (1896): "... habit diminishes the conscious attention with which our acts are performed."

It has also been reported that the learning may be influenced by mediation even though Ss do not report the conscious use of it. For example, Bugelski \& Scharlock (1952), employing the $\mathrm{AB}, \mathrm{BC}, \mathrm{AC}$, mediation paradigm, found facilitation of $\mathrm{AC}$ learning with no $S$ "consciously" resorting to the use of the B syllable. Russell \& Storms (1955) reported similar findings with norm-inferred mediational chains. However, Martin \& Dean (1964) found no evidence to support the interpretation of unconscious mediation in the RussellStroms task.

The present study was designed to explore the effects of practice beyond a criterion on verbal reports of mediating activity in a paired associates learning task. Additionally, the study was to serve as a partial replication of the Bugelski-Scharlock study.

\section{Method}

Three lists, each containing eight nonsense syllable pairs, were constructed from the 16 item lists used by Bugelski and Scharlock. The $\mathrm{AB}, \mathrm{BC}, \mathrm{AC}$ sequence was used with a "mixed" $\mathrm{AC}$ list consisting of four facilitation and four interference pairs. The $A$ and $C$ terms of a facilitation pair had been paired with a common $B$ term in the previous lists. The $A$ and $C$ terms of an interference pair had been paired with different $B$ terms in the previous lists. There were two forms of the final list: each $A$ and $C$ term of a facilitation pair of one form served in different interference pairs on the other form and vice versa.

The stimulus and stimulus-response pairs were typed on separate $3 \times 5$ in. white cards, photographed and made into $35 \mathrm{~mm}$. slides. Five different random orders of each list were constructed and were projected onto a white screen by means of a Carousel projector at a 2:2 second rate. There were no blank slides between orders and the anticipation method was used. Ss sat about $15 \mathrm{ft}$. from the screen.

Each $\$$ learned the first two lists to a criterion of two perfect trials (not necessarily consecutive). One group learned the third list to two perfect trials; the other group was given 10 additional trials beyond the second perfect trial. The interval between the end of one list and the beginning of the next was approximately $2 \mathrm{~min}$.

After reaching criterion on the third list, the stimuli of this list were read to $\mathrm{S}$ who was instructed to tell $\mathrm{E}$, "Exactly what came to your mind when you saw that syllable on the screen. If nothing but the response syllable, just say the response; if you thought of something else in addition to the response syllable, tell me what it was." When this procedure had been completed for each of the stimuli, $\mathrm{S}$ was read the stimulus and response terms of the final list and was asked, "Tell me what you did to learn the response syllable, what you thought of when you were trying to learn the response syllable."

The Ss were introductory psychology students at Syracuse University (summer session) who participated in experiments as a part of their course requirement. The design was a 2 by 2 by 2 factorial (criterion, sex, form of list) with five Ss in each cell. The Ss were assigned to the criterion conditions alternately and to the form of the list in two's, males and females being assigned separately according to this sequence.

\section{Results and Discussion}

A mixed analysis of variance on the mean number of trials to criterion on each list for each group yielded significant effects due to Lists $(F=28.915, d f=2 / 64$, $\mathrm{p}<.001)$, and the interactions Criterion by Sex by Form $(\mathrm{F}=9.512, \mathrm{df}=1 / 32, \mathrm{p}<.01)$, and Criterion by Sex by Form by List ( $F=5.992$, df $=2 / 64, p<.01)$. These interactions resulted from a differential effect of "Form" on learning $\mathrm{AB}$ and $\mathrm{BC}$ lists, an effect which must reflect a bias in assigning Ss to groups as "Form" did not differ until the AC list. A separate analysis was performed on the number of trials to criterion on the AC list and the only significant effect due to sex, with females requiring fewer trials than males $(F=4.355, d f=1 / 32, p<.05)$. Thus, except for sex, groups were reasonably equated on learning of the $\mathrm{AC}$ list.

A mixed analysis of variance (Criterion, Form of List, Kind of Pair, Trials) on correct anticipations for the first five trials on the $\mathrm{AC}$ list yielded significant effects due to Trials $(F=130.478, \mathrm{df}=4 / 128, \mathrm{p}<.001)$; Kind of Pair (Facilitation-Interference) $(F=13.524$, $\mathrm{df}=1 / 32, \mathrm{p}<.001)$; and Form by Kind of Pairs $(F=5.868$, $\mathrm{df}=1 / 32, \mathrm{p}<.05)$. Table 1 presents the mean correct

Table 1. Mean number of facilitation and interference pairs in each mediation category and number of correct responses over 5 trials as a function of Form of the $\mathrm{AC}$ List.

\begin{tabular}{llrrrrrr} 
Form & Pair Responses & ABC & Other & Total & \\
\hline \multirow{2}{*}{ Form 1 } & F & 11.00 & 0.55 & 2.75 & 3.20 & 0.60 \\
& 1 & 8.50 & -- & 2.40 & 2.40 & 1.60 \\
\hline \multirow{2}{*}{ Form 2 } & F & 10.45 & 0.65 & 2.30 & 2.95 & 1.05 \\
& 1 & 9.75 & -- & 3.00 & 3.00 & 1.00 \\
\hline
\end{tabular}


anticipations over 5 trials as a function of kind of pair and form of the AC 1ist. On form 1 of the AC list facilitation pairs were learned significantly better than interference pairs, $(p<.01)$ but the difference on form 2 did not attain significance $(p>.05)$.

For each $\mathrm{S}$, each pair of the AC list was classified as "direct" if S reported to the first series of questions that the response was all that had occurred to him when the stimulus had been presented on the last trial or "indirect" if $S$ reported any intervening activity before the response occurred. Each pair was further classified as "ABC-mediated" if $S$ reported learning it by the use of the ABC sequence; as "other" mediated if by any kind of associative aid; or "rote" if $\mathrm{S}$ reported only memorization, repetition, etc. In a mixed analysis of variance (Criterion, Sex, List Form, Kind of Pair) on the number of pairs reported as "direct," the only effect to reach significance was Criterion $(F=15.745$, $\mathrm{df}=1 / 32, p<.001$ ) indicating that more pairs were reported as direct in the overlearning condition. The mean number of pairs reported as direct in the two perfect criterion group was 4.35 and in the overlearning group was 6.55 . These results are consistent with the notion that post-criterion practice produces a decrease in mediational activity.

Table 1 contains the mean number of facilitation and interference pairs in each mediation category. An analysis of variance on the number of pairs reported as mediated yielded significant effects due to Kind of Pair $(F=6.427, \mathrm{df}=1 / 32, \mathrm{p}<.05)$ and the interaction, List Form by Kind of Pair $(F=8.208, \mathrm{df}=1 / 32, \mathrm{p}<.01)$ 。 Only on form 1 were a significantly $(p<.001)$ greater number of facilitation pairs reported as mediated, this being the same form on which there was better learning of facilitation pairs. In an analysis of variance on the number of facilitation pairs reported as $\mathrm{ABC}$ or Other, only the difference between $\mathrm{ABC}$ and other categories reached significance $(F=43.595, d f=1 / 32, p<.001)$.

One method of testing for "unconscious" mediation is to compare the learning rate for facilitation and interference pairs as a function of mediation category. Several problems arise with these comparisons, the most important of which would seem to involve the necessity for all kinds of categories to occur in a given $\mathrm{S}$ for both facilitation and interference pairs. Eight females and 11 males reported mediated (ABC or other) and rote learning in both facilitation and interference pairs. An analysis of variance (Sex, Kind of Pair, Mediation Category) on the mean correct response per pair per trial yielded significant effects due to Mediation Category $(\mathrm{F}=4.792, \mathrm{df}=1 / 17, \mathrm{p}<.05)$, a higher rate of learning occurring for the mediated than for the rote pairs. The mean correct anticipations per pair per trial for pairs reported as mediated was .714 , and for pairs reported as rote was .610. Although
Table 2. Mean correct response per pair per trial as a function of kind of reported mediation

\begin{tabular}{lcccc} 
Pair & $A B C$ & Other & $\begin{array}{l}\text { Total } \\
\text { Med }\end{array}$ & Rote \\
\hline $\begin{array}{llll}\text { Facilitation } \\
\text { Interference }\end{array}$ & .764 & .735 & .735 & .673 \\
& .667 & .667 & .564 \\
\hline
\end{tabular}

the effect of Kind of Pair did not reach significance, the possibility still might be raised that within the pairs verbalized as rote, facilitation pairs were learned at a faster rate than interference pairs, thus indicating some sort of unconscious facilitation by the $A B C$ chain. However, the difference in learning rate between facilitation and interference pairs did not approach significance either when both were reported as rote $(t=1.034$, $\mathrm{df}=18$ ) or when both were reported as mediated $(t<1)$. Since only half of the Ss were used in these comparisons, the mean overall learning rate of facilitation and interference pairs for each Mediation Category was determined on the basis of all Ss who used the category. These data are presented in Table 2 and corresponds generally to the data obtained from the $19 \mathrm{Ss}$.

Although these results do not support the findings of Bugelski \& Scharlock (1952) that facilitation pairs were learned better than interference pairs in the absence of verbalized mediation of the common intervening term, there were several differences between the Bugelski-Scharlock study and the present one. The most important would seem to involve the time interval between the learning of the three lists. Bugelski and Scharlock used a 48-hr. interval while the interval in the present study was only $2 \mathrm{~min}$. Bugelski reported that no $\mathrm{S}$ verbalized the common intervening term while $15 \mathrm{Ss}$ in the present study reported using at least one. Another methodological difference may have involved the intervening procedure, the details of which were not reported in the Bugelski-Scharlock study.

\section{References}

Barnes, J. M., \& Underwood, B. J. "Fate" of first-list associations in transfer theory. J. exp. Psychol., 1959, 58, 97-105. Bugelski, B. R. \& Scharlock, D. P. An experimental demonstration of unconscious mediated association. J. exp. Psychol., 1952, $44,334-338$.

James, W. The principies of psychology. Vol. I. New York: Holt, 1896.

Martin, R. B., \& Dean, S. J. Implicit and explicit mediation in paired-associate learning. J. exp. Psychol., 1964, 66, 21-27.

O'Brien, F. J. A qualitative investigation on the effect of mode of presentation upon the process of learning. Amer. J. Psychol., $1921,32,249-283$.

Reed, H. B. Associative aids: II. Their relation to practice and the transfer of training. Psychol. Rev., 1918, 25, 257-285.

Russe 1l, W. A., \& Storms, L. H. Implicit verbal chaining in pairedassociate learning. J. exp. Psychol., 1955, 49, 287-293.

Solomons, L. M. Autamatic reactions. Psychol. Rev., 1899, 6, 376-394. 